\title{
Intermittent Catheterisation versus Percutaneous Suprapubic Cystostomy in the early Management of Traumatic Spinal Cord Lesions
}

\author{
F. Noll, ${ }^{2}$ O. Russe, ${ }^{2}$ E. Kling, ${ }^{2}$ U. Bötel, ${ }^{2}$ F. Schreiter ${ }^{1}$ \\ ${ }^{1}$ Urologische Abteilung der Med. Fakultät der Universität Witten-Herdecke im \\ Verbandskrankenhauses Schwelm, 5830 Schwelm Germany (FDR) ${ }^{2}$ Abteilung \\ für Rückenmarksverletzte des 'Bergmannsheil' Bochum, 4630 Bochum Germany \\ (FDR).
}

\section{Summary}

Spinal injury patients initially treated by intermittent catheterisation (IUC) and those who received a fine-bore suprapubic catheter (SPC) have been reviewed.

The results show that fine-bore suprapubic catheterisation seems to be superior to intermittent catheterisation because the rate of urinary tract infections is significantly lower in the SPC-group $\left(50^{\circ}{ }_{0}\right)$ than in the IUC-patients $\left(71,9^{\circ}{ }_{0}^{\circ}\right)$, and the first infecting organisms in the SPC-group differ from those in the IUC-group and are much more easily treated by antibiotic therapy.

Key words: Spinal cord injury; Fine-bore suprapubic catheterisation; Intermittent urethral catheterisation; Early infection of the neuropathic bladder.

Intermittent catheterisation was, for many years, the treatment of choice for bladder drainage in the acute phase following spinal cord injury. Conventional suprapubic cystostomy, preferred during World War II by the US-Navy is no longer advocated because of the detrimental effects on the urinary tract. In recent years, however suprapubic drainage has been revived as an early urological management technique in paraplegic patients using fine-bore (percutaneous) suprapubic cystostomy.

At the Spinal Injury Centre of the Bergmannsheil Clinic in Bochum, all patients seen in the acute phase of spinal cord injury before 1979 had intermittent catheterisation (IUC). After 1979, fine-bore suprapubic catheterisation (SPC) became our method of choice. To compare the two methods of bladder drainage we reviewed the patients treated at our hospital with IUC (1976-1979) and SPC (1979-1983), and present the results here.

\section{Patients and methods}

A total of 134 patients treated with IUC and 128 patients treated with SPC 
Table I Selection of patients

1. Sterile urine on admission

2. More than 3 urine cultures

3. Duration of catheterisation longer than 20 days

4. Foley catheter not more than 4 days in situ

Entry into trial: 32 patients in the IUC-group

54 patients in the SPC-group

Table II Distribution of sex, age, neurological level of lesion and delay in admission

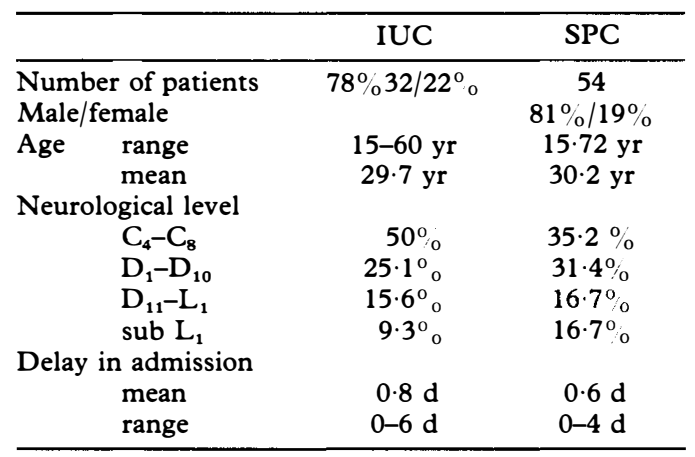

were selected for study. Selection was done according to the criteria shown in Table I to ensure comparable results.

The two groups were further comparable as regards sex distribution, age, neurological level of lesion and delay before admission (Table II).

In the IUC-group we used the well-known 'non-touch-technique' as described by Guttmann and Frankel (1966). The Cystofix System was employed for SPC.

The SPC was inserted initially on admission to the Spinal Cord Centre. The bladder was filled with $400-500 \mathrm{ml}$ of an $0.9^{\circ} \% \mathrm{NaCl}$ solution and a fine-bore suprapubic catheter inserted according to the manufacturer's instructions (Cystofix-System, Fa. Braun, Melsungen). The punch cystostomy should only be done by a doctor familiar with this technique. Safe performance of percutaneous cystostomy is greatly facilitated by a markedly distended bladder. Sometimes bladder filling through a transurethral catheter is necessary. The procedure itself should be performed under local anaesthesia. The suprapubic area is shaved and prepared with an alcoholic PVJ-solution in sterile fashion.

Exactly in the midline approximately 2 to $3 \mathrm{~cm}$ above the pubic symphsis the skin and the underlying tissue is infiltrated with a local anaesthetic. A long spinal needle is used for that procedure so prospecting for urine to locate the bladder is possible. Then a stab incision is made in the skin with a scalpel blade. The cannula is then pushed posteriorly until urine returns. The specially designed cystostomy tube is then passed through the cannula into the bladder. The tube is fixed to the skin with a nonabsorbable suture and a sterile dressing is applied. 


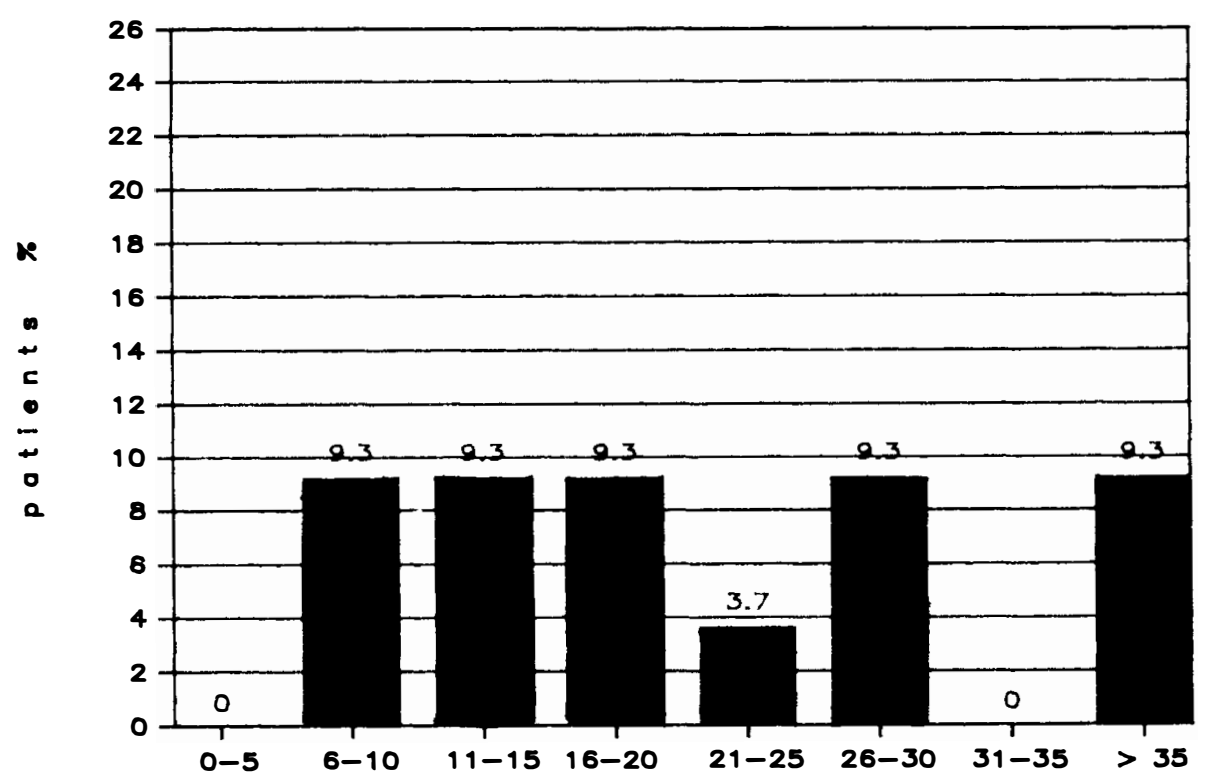

Figure 1 Suprapubic catheter.

The bladder was then drained continuously into a closed drainage system. At the end of the spinal shock period, the SPC was clamped for $2-4$ hours until micturition occurred.

\section{Results}

\section{Establishment of micturition}

The time of first spontaneous or assisted micturition was statistically not significantly different in the two groups.

\section{Urinary tract infection}

The time of first infection does not differ significantly in the two groups, nor does the number of infected patients, as is shown in Figure 1.

However, if the distribution function of the first bacterial invasion is considered, the differences between the two groups become more obvious (Fig. 2). The probability of infection within the first 35 days is $71.9 \%$ in the IUC, but only $50 \%$ in the SPC-group.

\section{First infecting organisms}

Not only is there a statistically significant difference in the number of infected patients in the two groups, but also the first infecting organisms show a pronounced difference (Table III). 


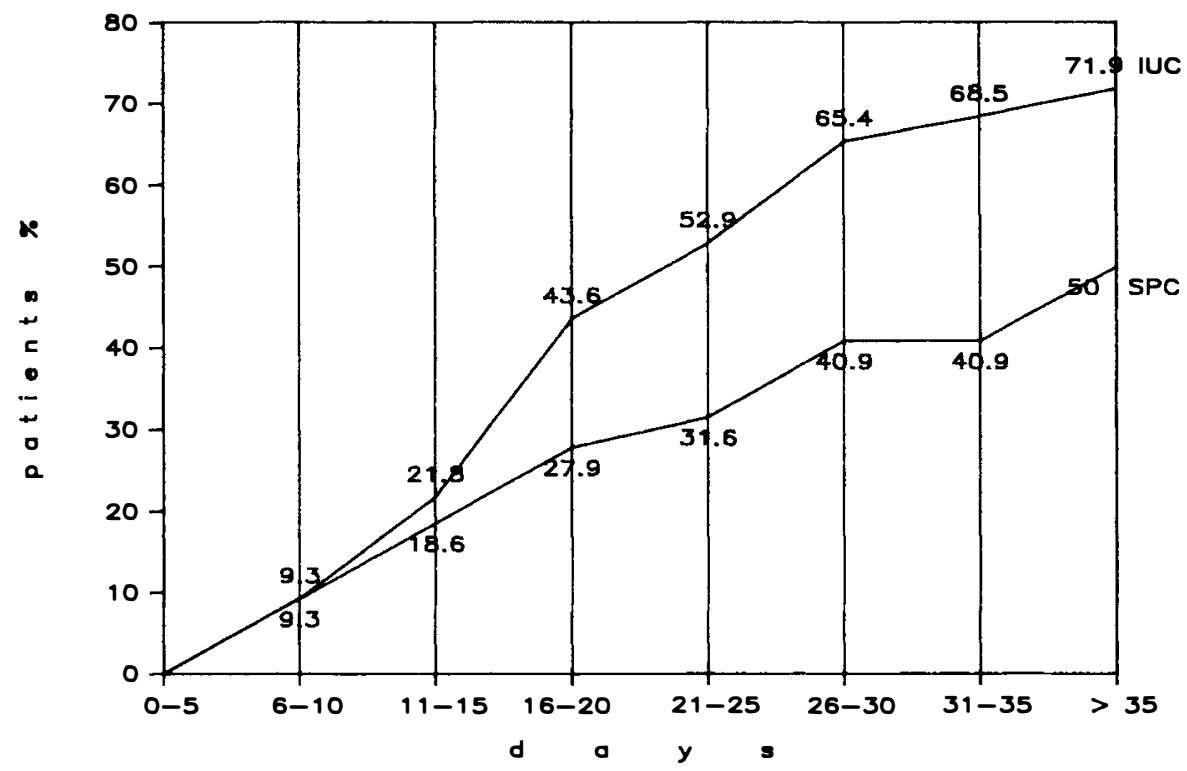

Figure 2 Distribution of first infection.

Table III First infecting organisms

\begin{tabular}{|c|c|c|}
\hline & IUC & SPC \\
\hline E. Coli & $34 \cdot 8^{\circ}{ }_{0}$ & $18 \cdot 5^{\circ} \mathrm{o}$ \\
\hline Proteus & $26 \cdot 1^{\circ}$ & $3 \cdot 7^{\circ} \circ$ \\
\hline Pseudomonas & $21 \cdot 7^{\circ} \mathrm{o}$ & $11 \cdot 1^{\circ} \%$ \\
\hline Staphylococcus aureus & $17 \cdot 4^{\circ}{ }_{0}^{\circ}$ & $25 \cdot 9^{\circ} \mathrm{o}$ \\
\hline Staphylococcus epidermidis & - & $14 \cdot 8^{\circ}{ }_{o}$ \\
\hline Streptococcus faecalis & $4 \cdot 3^{\circ}$ o & $11 \cdot 1^{\circ} \mathrm{o}$ \\
\hline Others & $4 \cdot 3^{\circ}$ & $25 \cdot 9^{\circ}{ }_{0}$ \\
\hline
\end{tabular}

Table IV Resistences for E. Coli

\begin{tabular}{|c|c|c|}
\hline & IUC & SPC \\
\hline Ampicillin & $75^{\circ}{ }_{\mathrm{o}}$ & $40 \%$ \\
\hline Tetracycline & $87 \cdot 5^{\circ}{ }_{0}$ & $25^{\circ}$ o \\
\hline Cephalosporin & $50^{\circ}$ & $20^{\circ}{ }_{0}$ \\
\hline SXT & $75^{\circ}{ }_{0}^{\circ}$ & $0^{\circ}{ }_{0}^{\circ}$ \\
\hline Nitrofurantoin & $50^{\circ}{ }_{0}$ & $20^{\circ}{ }_{0}^{\circ}$ \\
\hline Nalidixin acid & $50^{\circ}{ }_{0}$ & $0^{\circ}{ }_{o}$ \\
\hline Oral drug therapy possible & $75^{\circ}$ o & $100^{\circ}{ }_{0}$ \\
\hline
\end{tabular}

In the IUC-group the most frequent organism is E. coli, directly followed by Proteus, while in the SPC-group Staphylococcus aureus is followed by E. coli. Proteus infections in this group were remarkably less common than with IUC $\left(3 \cdot 7^{\circ}{ }_{\mathrm{o}}\right.$ compared with $\left.26 \cdot 1_{\%}^{\circ}\right)$.

In summary, in the IUC-group an infection with so-called 'problem bacteria' is more likely to occur than in the SPC-group. To confirm this result we re- 
viewed the resistograms of the observed bacteria (Table IV). The result for E. coli will be given as an example.

Resistances for $E$. coli

Only those drugs which were available during both time periods (1976-1979 and 1979-1983) were considered.

\section{Complications of IUC and SPC}

The complications encountered with IUC are well known and will not be discussed in detail here. To reduce complications with SPC, only those physicians familiar with the method of insertion should use the fine-bore cystostomy. Frequent complications of SPC are:

\section{Haematuria}

Haematuria was usually mild and cleared spontaneously under good diuresis.

2. Skin infections

Skin infection at the point of insertion occurred occasionally. A strict sterile regime during insertion, good skin disinfection and the use of a special polyurethane covering sheet reduced infections to an acceptable degree in our SPC-group.

3. Blocking of the catheter

Blockage of the thin $8 \mathrm{~F}$ catheter is one of the main disadvantages of SPCdrainage. However, under a fluid regime which guarantees the production of $1500 \mathrm{ml}$ urine per day and an additional drug therapy with L-Methionin to fix the urine $\mathrm{pH}$ between 5 and 6 , the propensity towards blockage can be significantly reduced.

4. Intraperitoneal injury

Intraperitoneal injury is one of the most serious problems encountered with the SPC-method. However, if the bladder is filled to near full extension, the insertion technique is performed correctly, and all contra-indications to SPC have been taken into account, then injury to the intestine is very rare. In our SPC-group we saw only one intraperitoneal injury. Laparatomy has never been necessary.

\section{Conclusions}

The results show that SPC is superior to IUC in the acute phase of spinal cord injury. The reasons for this rather provocative statement are as follows:

1. The probability of urinary tract infection during the spinal-shock phase is lower with SPC than with IUC.

2. The first infecting organisms are not usually the so-called 'problembacteria'.

3. Oral drug therapy can be instituted in the SPC-group in nearly all patients in an initial urinary tract infection.

4. The cost of SPC-treatment is much lower than with IUC. 
5. IUC is more time-consuming than SPC.

Furthermore Peatfield, Burt and Smith have shown that the long-term results with SPC are comparable to those obtained with IUC.

\section{References}

Cook JB, Sмiтн PH 1976 Percutaneous suprapublic cystostomy after spinal cord injury. British fournal of Urology 48:119-121.

GRUNDY DJ, et. al. 1983 A comparison of fine-bore suprapubic and an intermittent urethral catheterisation regime after spinal cord injury. Paraplegia 21:227-232.

GutTMANN L, Frankel H 1966 The value of intermittent catheterisation in the early management of traumatic paraplegia. Paraplegia 4:63-84.

HACKLER RH 1982 Long-term suprapubic cystostomy drainage in spinal cord injury patients. British fournal of Urology 54:120-121.

KLING E 1984 Infektgefährdung Querschnittsgelähmter mit Blasenlähmung in der spinalen Schockphase bei suprapubischer Harnableitung im Vergleich zu intermittierendem Katheterismus. Promotionsarbeit, Universität Bochum, to be published.

Peatfield RC, et al. 1983 Suprapubic catheterisation after spinal cord injury: A follow up report. Paraplegia 21:220-226. 